\title{
Bebês nas creches e nos espaços urbanos cariocas
}

\author{
Babies at day care centers in urban spaces in Rio \\ Bebés en guarderías y espacios urbanos cariocas \\ MARCIA DE OlIVEIRA GOMES GiL* \\ VERA MARIA RAMOS DE VASCONCELLOS**
}

\begin{abstract}
RESUMO
O direito à educação de bebês é discutido no cenário da cidade do Rio de Janeiro, entre os anos 2009 e 2016, gestão dupla de uma mesma prefeitura. As vagas na educação infantil municipal e as matrículas no berçário são investigadas após a construção de novas edificações (GIL, 2018). O reconhecimento social do direito à creche para todos os bebês e crianças pequenas, independentemente de critérios de vulnerabilidade, é o ponto de partida das discussões. A legislação brasileira é apresentada e as ações do Ministério Público são analisadas. Os resultados revelam que, na relação com o direito à educação de bebês, mesmo com as novas edificações, específicas para a educação infantil, o número de matrículas cresce nos agrupamentos de crianças com mais idade e no berçário vêm sendo reduzidas a cada ano. Acrescenta-se a isso a diminuição de creches municipais em tempo integral.
\end{abstract}

Palavras-chave: Bebês. Creche. Direito à educação. Cidadania.

\begin{abstract}
The article discusses the right to education of infants in the context of the city of Rio de Janeiro and as a period of analysis, the years of 2009 to 2016, double management of the same mayor. The number of vacancies in municipal public education is investigated, focusing on enrollment in the nursery, in particular after the construction of new educational equipment (GIL, 2018). The citizenship of infants and the social recognition of the right to daycare for all children, regardless of vulnerability criteria, is the starting point for all analyses. The results point out that in relation to the right to the education of babies, even with the new building facilities, specific to child education, the number of enrollment in the nursery have being reduced every year, although there is growth in the other groups. It adds to this the reduction of full-time daycares.
\end{abstract}

Keywords: Babies. Day care. Education rights. Citizenship.

\section{RESUMEN}

El artículo examina el derecho a la educación de bebés teniendo como escenario la ciudad de Rio de Janeiro y como período de análisis, los años del 2009 a 2016, doble gestión de un mismo municipio. El número de vacantes en la Educación Infantil pública municipal es investigado, con foco en las matrículas de maternal, especialmente, después del desarrollo de nuevos equipamientos educativos (GIL, 2018). La ciudadanía de los bebés y el reconocimiento social del derecho a la guardería para todos los niños, independientemente de los criterios de vulnerabilidad, es el punto de partida de todos los análisis Los resultados apuntan que la relación con el derecho a la educación de los bebés,incluso con las nuevas construcciones, específicas para la Educación Infantil, el número de matrículas en maternal se ha reducido cada año, aunque haya crecimiento en los demás grupos. Adicionalmente, se ha disminuido las guarderías de tiempo completo.

Palabras claves: Bebés. Guardería. Derecho a la educación. Ciudadanía.

\footnotetext{
*Universidade do Estado do Rio de Janeiro. Doutorado em Educação pela Uerj. <https://orcid.org/0000-0002-8515-9007>. E-mail: <marciagil@globo.com>.

**Professora titular do Departamento de Educação da Uerj. Pós-Doutorado em Psicologia. <https://orcid.org/0000-0001-9544-6600>. E-mail: < vasconcellos. vera@gmail.com>.
} 


\section{INTRODUÇÃO}

Este artigo aborda algumas reflexões sobre políticas brasileiras destinadas às crianças, com olhar privilegiado para os bebês. Representa um exercício de constante confronto de dualidades: de um lado, legislações e direitos; e, de outro, ineficiência e até inexistência de ações públicas destinadas à materialização de tais direitos, especialmente no que tange aos direitos educacionais de crianças de menor idade. As fragilidades que envolvem o tema crianças como sujeitos titulares de seus direitos são discutidas em paralelo à preocupação de entender em que medida a utilização da palavra criança incorpora às políticas educacionais o direito dos bebês. Serão os bebês concebidos como titulares de direitos?

O cenário é a cidade do Rio de Janeiro, grande centro urbano com território de $1.182,296 \mathrm{~km}^{2}$ e densidade demográfica de $5.249 \mathrm{hab} . / \mathrm{km} .{ }^{1}$ Conhecida e falada por suas impressionantes belezas naturais, a chamada Cidade Maravilhosa tem montanhas e mar e é considerada a capital cultural, com um povo aberto às novidades e a acolher turistas. A relação da cidade com os bebês pode ser analisada a partir da existência de 12 maternidades públicas e de uma casa de parto $^{2}$ que acolhem os novos cidadãos cariocas.

A cidade conta com parques e praças espalhados pelos bairros, especialmente aqueles com maior poder aquisitivo. Nos finais de semana, as vias próximas às praias são liberadas ao lazer das famílias. Para as camadas populares, as opções são mais escassas e simples. Alguns parques contam com brinquedos específicos para bebês e crianças pequenas, além de fraldário. Há neles possibilidades de brincadeiras e diversão e algumas vezes a presença de agenda cultural, com programações gratuitas voltadas para crianças de diversas idades.

Paradoxalmente à sua beleza, a cidade é marcada por agressões de diferentes ordens. O tráfico, a bandidagem e a violência policial são presenças constantes nas mídias. Cada vez menos se encontram na cidade ruas e becos livremente ocupados por crianças brincando. Limitações que impactam as experiências infantis e a possibilidade de as crianças viverem suas infâncias ao ar livre, nos espaços urbanos.

Roberto DaMatta (1997, p. 14), no livro A casa, a rua: espaço, cidadania, mulher e morte no Brasil, instaura a "rua" como categoria sociológica, uma vez que esta

[...] não designa simplesmente espaços geográficos ou coisas físicas comensuráveis, mas acima de tudo entidades morais, esferas de ação social, províncias

\footnotetext{
1 Dados do Armazém do Rio de Janeiro.

2 Disponível em: <http://www.rio.rj.gov.br/web/sms/maternidades>. Acesso em: 20/03/2018
}

éticas dotadas de positividade, domínios culturais institucionalizados e, por causa disso, capazes de despertar emoções, reações, leis, orações, músicas e imagens esteticamente emolduradas e inspiradas.

Muitas vezes, a rua é vista e vivenciada pela criança como uma extensão da casa, um lugar de encontro para brincar e conversar (MÜLLER, 2007). No entanto, para poucas crianças da cidade, a rua tem sido mais espaço de encontros plurais e das diferenças, características típicas dos centros urbanos e muito menos lugar de descobertas, convivência e aprendizagens. Castro (2004) remete àqueles a quem são impedidos o despertar de emoções, regras e de outras experiências cunhadas em encontros e na coletividade.

Consideram-se as cidades como espaços organizados para receber seus cidadãos, com instituições e organização urbanas voltadas para o acolhimento de diferentes necessidades: lazer, segurança, saúde e educação. No entanto, a cidade do Rio de Janeiro está distante de atender com equidade à sua população, ignorando diferenças, em especial as etárias. Embora "para todos", a cidade não é, de fato, de todos. Tal fenômeno não se restringe apenas à cidade em questão, já que Tonucci (2009, p. 151) afirma: "Porque la ciudad, su administración, ha elegido como ciudadano prototipo a un ciudadano varón, adulto $\mathrm{y}$ trabajador. Con la consecuencia de que, en esta ciudad, han desaparecido los ancianos, los discapacitados y los niños".

A creche é também um ambiente de socialização, de convívio e construção de relacionamentos. Da mesma forma que outros espaços urbanos, a creche, como instituição, nem sempre está disponível para as crianças, especialmente aquelas de menor idade: os bebês e crianças pequenas (BRASIL, 2017). Como espaço livre, as crianças muitas vezes se encontram impedidas de frequentar as creches por haver poucas opções e, nas existentes, faltam vagas, o que se configura como violação de direitos.

Dentro desse cenário, o artigo dedica-se a investigar a relação da cidade com os bebês e com as crianças bem pequenas (BRASIL, 2017), especialmente na garantia do direito à educação pública, gratuita e de qualidade. Será a cidade tão maravilhosa também com os seus pequenos?

O Rio de Janeiro tem uma rede escolar extensa. Dela fazem parte 508 unidades públicas específicas de educação infantil, entre Espaços de Desenvolvimento Infantil (EDIs) e creches, divididos em 11 Coordenadorias Regionais de Educação/CRE ${ }^{3}$, e a educação infantil formal conta com 1.957 turmas e 44.543 crianças matriculadas. ${ }^{4}$ A pesquisa que dá origem a este artigo analisou as

\footnotetext{
3 Dados da Secretaria Municipal de Educação referentes ao ano de 2018.

4 Dados da Secretaria Municipal de Educação do Rio de Janeiro.
} 
matrículas em creche, especialmente no berçário, ao longo da gestão dupla de uma prefeitura (2009 a 2016). Os dados verificados em conformidade com as leis e com as políticas balizam a importância política que a cidade tem, servindo muitas vezes de modelo para outros municípios (GIL, 2018).

Foi analisado o repertório nacional de leis, políticas públicas e marcos históricos. Elementos que apontam concepções que se desenrolam a cada tempo histórico e ao sabor da forma como a criança e o bebê são percebidos, em especial por aqueles que detêm poder de influência na elaboração e execução de políticas públicas.

\section{LEIS, MARCOS E POLÍTICAS: OS BEBÊS EM FOCO}

Muitas são as ações destinadas às crianças na sociedade brasileira. Chamam a atenção algumas, historicamente importantes, como a criação do Departamento Nacional da Criança (DNCr), em 1940; do Serviço de Assistência ao Menor (SAM), em 1941; e da Legião Brasileira de Assistência (LBA), em 1942. Na perspectiva de Nunes (2011) e Perez e Passone (2010), essas iniciativas são consideradas um marco no atendimento a famílias, crianças e jovens, principalmente os mais pobres e necessitados.

Vinculado ao Ministério da Educação e Saúde, o DNCr tinha por objetivo "[...] criar viva consciência social da necessidade de proteção à díade materno-infantil [...]" (PERES; PASSONE, 2010, p. 657). Rosemberg (1992) sinaliza que a implantação do "Clube de Mães" foi uma das primeiras ações na parceria do Fundo das Nações Unidas para a Infância (Unicef) com o DNCr. Tal clube pretendia "[...] fixar e valorizar a mulher no lar, pela educação das crianças pequenas" (ROSEMBERG, 1992, p.3), fortalecendo o modelo de assistência social e do voluntariado, já amplamente utilizado nas práticas de assistência social às crianças pequenas no Brasil. Ao enfatizar a díade mãe-bebê, o DNCr não dá destaque ao sujeito em questão deste artigo - o bebê, referido, nessa determinação de forma indireta, sujeitado a uma relação (mãe-bebê). Assim, o departamento, criado para proteger a infância, não personaliza o bebê.

O Código de Menores, no art. 13, estabelecia, sobre a educação das crianças, que o governo federal estava autorizado "[...] a auxiliar, de acordo com a lei de subvenções, as creches, os institutos de gotta de leite, ou congeneres de assistência à primeira infância e puericultura" (BRASIL, 1927). Assim, ficaram os bebês incluídos nas ações de cuidado, sem serem visibilizados no texto e sem haver nenhuma menção à responsabilidade ou preocupação para com a educação dessas crianças em instituições formais.
A Legião Brasileira de Assistência (LBA) iniciou as suas atividades em 1942, amparada pelo Decreto Federal no 4.830, constituindo-se em uma associação “[...] fundada com o objetivo de prestar, em todas as formas úteis, serviços de assistência social, diretamente ou em colaboração com instituições especializadas" (BRASIL, 1942). No ano de 1977, a LBA implementou o Projeto Casulo, inicialmente, em caráter experimental, no Rio Grande do Sul, no Rio Grande do Norte, no Ceará e em Alagoas, porém, até a década de 1980, o projeto já havia se estendido para todo o território nacional.

Assim, sob o lema "Vamos fazer uma creche!", a LBA incentivava o empresariado e as comunidades à criação de creches, com o objetivo de alcançar a ousada meta de atender a cerca de 1 milhão de crianças e famílias com baixos custos operacionais, uma vez que as Creches Casulo se estruturavam "[...] sobre bases materiais e humanas oferecidas pelas comunidades" (TATAGIBA, 2011, p. 152). As creches recebiam crianças desde o nascimento, em uma perspectiva assistencialista.

Tais políticas desenhavam os direitos à infância para as crianças mais pobres de todas as idades, pois assistir e proteger, por meio de ações focadas na figura da mãe, parecia ser o compromisso das ações que se desdobravam nas políticas destinadas ao sujeito - criança - à época.

Em 1971, em plena ditadura militar, a Lei no 5.692/71 desobrigou os governos de qualquer incumbência educacional com crianças pequenas. No que tange à educação das crianças de 0 a 6 anos, Lanter-Lobo (2011) esclarece que o que estava previsto na lei era que os sistemas de ensino deveriam "velar" para que as crianças recebessem educação em instituições maternais, jardins de infância ou equivalentes (art. 19, §2).

Os direitos educacionais dos bebês e crianças mais novas não foram estabelecidos, deixando-os esquecidos e mais uma vez invisibilizados no discurso oficial, realidade que adensa a necessidade de avaliar as motivações e os interesses que estão por detrás das políticas destinadas às crianças.

A Constituição Federal (BRASIL, 1988) e a Lei de Diretrizes e Bases da Educação Nacional (LDBEN) $n^{\circ}$ o 9.394 (BRASIL, 1996) garantem a educação infantil como primeira etapa da educação básica e definem seu público: as crianças até 5 anos. ${ }^{5}$ Depois, há a promulgação da EC no 59/2009 e a implantação da Lei no 12.796/2013, que determinam a obrigatoriedade da pré-escola (4 e 5 anos), fragmentando a unidade e a integralidade da educação infantil e deixando a creche ( 0 a 3 anos) frágil, perante as outras etapas do nível educativo.

Dessa forma, o lugar do bebê na legislação brasileira acaba por permanecer vinculado à figura da mãe, em

\footnotetext{
5 Antes, 6 anos e, a partir da Emenda Constitucional no 53/2006, 5 anos.
} 
expressões como "materno-infantil", ou incluído na palavra criança. Nesse jogo semântico, o vocábulo criança é utilizado de forma ampla e as garantias legais destinadas aos bebês tornam-se incorpóreas. Neste artigo, pensar em proteção faz parte do repertório de ações para a infância e pensar a cidadania dos bebês sugere formas ativas de garantia de todos os direitos. Sarmento (2007, p. 42) declara que:

\begin{abstract}
A cidadania da infância [...] assume um significado que ultrapassa as concepções tradicionais, na medida em que implica o exercício de direitos nos mundos de vida, sem obrigatoriamente estar subordinada aos dispositivos da democracia representativa (ainda que estes não sejam, por esse facto, menos importantes). Tampouco, o reconhecimento dos direitos da cidadania - em que a dimensão da participação das crianças assume um relevo crescente - implica, por esse facto, uma restrição nas exigências de proteção das crianças pelos adultos, nomeadamente pelas famílias e pelo Estado. É no balanço ente estas duas posições - a proteção e a participação - que se exprime o melhor interesse das crianças.
\end{abstract}

Embora as determinações legais nos diferentes tempos históricos citem a criança, com distintas intencionalidades, os bebês são pouco ou nada referidos. A palavra bebê não é encontrada na Constituição Federal (BRASIL, 1988) e nem na LDBEN (BRASIL, 1996). Mesmo no Estatuto da Criança e do Adolescente (ECA) (BRASIL, 1990), legislação voltada à proteção integral de crianças e adolescentes, a palavra bebê aparece apenas uma vez (art. 14, §3을, referindo-se à atenção odontológica. Se a forma de busca é alterada e o foco migrar para a faixa etária, no ECA (BRASIL, 1990, art. 54, IV) e nas Diretrizes Curriculares Nacionais para a Educação Infantil (DCNEIs) (BRASIL, 2009, art. 3ํ), encontra-se a determinação clara do direito à educação a partir do nascimento (idade 0$).{ }^{6}$ São essas as principais referências que privilegiam em seus textos as crianças de menor idade.

Diante disso, discutir os direitos dos bebês, quase sempre incluídos em textos que permitem subjetivações e sob o risco de serem invisibilizados, faz-se necessário, pois as leis, embora afirmem direitos, parecem carecer de mecanismos que os garantam, que deem visibilidade à cidadania dos bebês e de fato se traduzam em práticas. Isso dá ao discurso político a possibilidade de manter-se distante da garantia dos direitos dos bebês à educação.

\footnotetext{
6 A CF (BRASIL, 1988) e a LDBEN no 9.394 (BRASIL, 1996) definem o público da educação infantil como crianças até 5 anos de idade, indefinindo a idade de entrada.
}

\section{DISPOSITIVOS LEGAIS FEDERAIS E OS DIREITOS DOS BEBÊS}

O Fundo de Manutenção e Desenvolvimento da Educação Básica e de Valorização dos Profissionais de Educação (Fundeb - BRASIL, 2007) incluiu a educação infantil como etapa de ensino com destinação de recursos, constituindo-se numa conquista. Porém, há neles fatores de ponderação ${ }^{7}$ que definem valor/aluno/ano em cada etapa educacional. $\mathrm{O}$ que acaba por destinar à educação infantil os mesmos percentuais do ensino fundamental urbano, ignorando que a especificidade do trabalho da educação infantil impõe gastos diferenciados do restante da educação básica. Assim como a creche exige maior disponibilidade de recursos, quando comparada com a pré-escola e mais ainda quando a referência é o berçário. Tal descompasso entre custos e custeio pode se caracterizar como entrave para que as crianças tenham ampliado o acesso à creche, e os bebês, acesso ao berçário de tempo integral.

Mais recente política pública federal destinada a essa faixa etária, a Ação Brasil Carinhoso ${ }^{8}$ (BRASIL, 2012), se constituiu em política voltada a impulsionar os municípios na organização do atendimento educacional à creche. $\mathrm{O}$ programa instituía a distribuição de recursos para sujeitos sociais em situação de pobreza à medida que as injustiças se perpetuassem na sociedade (SILVEIRA et al., 2015). Ao longo de sua existência, a ação beneficiou diferentes municípios, com matrícula nova concretizada na rede pública. Associado a ela e com base na Portaria Ministerial no 19, de 27 de dezembro de 2013 (BRASIL, 2013), os municípios recebiam por criança, em horário parcial, a quantia de $\mathrm{R} \$ 1.142,70$ e, em caso de matrícula em horário integral, o valor passaria para $\mathrm{R} \$ 1.486,62$. As creches conveniadas também foram contempladas com valores diferenciados: matrículas em horário parcial, $\mathrm{R} \$ 914,23$ e em horário integral, $\mathrm{R} \$ 1.257,07$. O valor da Ação Brasil Carinhoso repassado aos municípios e Distrito Federal no ano de 2014 foi de $\mathrm{R} \$ 765.646 .689,40$, equivalente a $0,65 \%$ dos recursos previstos para o Fundeb no ano de 2014, constituindose, assim, em uma grande oportunidade de ampliação do acesso à educação infantil a bebês e crianças de até 3 anos.

Como política que considerou as crianças mais novas como sujeitos de direitos, a ação Brasil Carinhoso buscou meios que assegurassem o acesso à educação, ao

\footnotetext{
${ }^{7}$ Foram criados pensando na distribuição proporcional das receitas, considerando que algumas etapas/modalidades podem ser mais dispendiosas que outras por exigirem maior utilização de insumos.

8 Programa instituído pela Resolução no 6, de 24 de abril de 2007. É parte das ações do Plano de Desenvolvimento da Educação (PDE) do Ministério da Educação.
} 
mesmo tempo em que previa recursos que possibilitassem a ampliação de qualidade às creches. A forma como os municípios se apropriaram dessa política deve ser uma preocupação constante dos pesquisadores da área. É importante saber se, ao realizar as novas matrículas, à creche foi garantida a igualdade de possibilidades de acesso para as crianças de diferentes faixas etárias nos grupamentos de berçário e maternal. Da mesma forma que a palavra criança não dá conta da especificidade dos bebês, a palavra creche não garante a existência de matrículas no berçário.

Assim, uma nova prática discursiva precisa ser criada para contemplar e concretizar a compreensão dos bebês como sujeitos de direitos, pois não pode haver diferenças ou discriminações entre sujeitos de direitos, sejam estas etárias, sejam estas sociais. Ferreira (2004, p. 1) afirma:

[...] não é indiferente o desigual conhecimento e reconhecimento das diferentes idades de vida como realidades humanas e sociais relevantes, dos que contam ou não como seres sociais e da sua importância no quadro da hierarquização das categorias sociais: o adulto, o jovem, a criança e os idosos.

Outra categoria pode ser acrescentada: os bebês, invisíveis e marginais na elaboração das políticas públicas. Uma invisibilidade que confere a eles destaque apenas em situações que afetam a sua integridade, como negligências e violências. No entanto, não seria a obscuridade que cerca seus direitos um tipo de violência?

Sobre essa questão, poucas são as conquistas sociais e as garantias de direito conferidas aos cidadãos de pouca idade. Resta a questão: quem são os bebês e qual sua importância para aqueles que elaboram e decidem as políticas públicas? Rosemberg (s/d, p.6) lembra que as discussões sobre os direitos dos bebês nas políticas educacionais ganham uma dimensão ampliada a partir da comparação com outros grupos demográficos:

À quase invisibilidade pública das crianças pequenas, deve-se acrescentar o padrão demográfico contemporâneo que, tendo reduzido o número de nascimentos e prolongado a esperança de vida, torna muito curta a duração da pequena infância frente à trajetória de vida, a despeito de essa duração não ser curta para a própria criança pequena hoje (é sua vida toda) e ser fundamental para essa pessoa no futuro.

O tempo da creche passa rápido, urgem ações de garantia de direitos. É nesse contexto que a trama dos direitos das crianças se torna frágil e suscetível ao esgarçamento, ao retrocesso e à invisibilidade. Por essa razão, é essencial, ao se discutir e garantir o direito das crianças à creche, evidenciar os direitos dos bebês e torná-los publicamente reconhecidos, fazendo do seu cumprimento uma exigência social.

\section{OS BEBÊS E O ACESSO À CRECHE PÚBLICA DA CIDADE}

Nesse sentido, vale resgatar Arendt (2008), que afirma que a política surge não no homem, mas sim entre os homens, como uma forma de relação, envolvendo pluralidades e subjetividades. A partir dessas relações, surgem políticas permeadas por intencionalidades dentro de outros acordos e relações previamente estabelecidos (ARAÚJO, 2017).

A pesquisa realizada na cidade do Rio de Janeiro (GIL, 2018) privilegiou análises referentes à faixa etária de 0 a 1 ano e 11 meses, grupamento do berçário, em especial as questões relativas ao aumento ou diminuição de matrículas. O estudo contemplou dados de oito anos no período de gestão dupla da cidade (2009 a 2016).

Embora o direito à educação esteja estabelecido constitucionalmente, o acesso para as crianças menores não é previsto em sua universalidade, nem mesmo no atual Plano Nacional de Educação (BRASIL, 2014). As oportunidades de acesso ainda não são garantidas pelos municípios, gerando desigualdades e deixando os bebês com poucas garantias no cenário das políticas públicas e com oportunidades desiguais no exercício de cidadania.

A pesquisa observou e identificou a política pública municipal educacional (2009-2016) voltada para o trabalho e atenção com as crianças da creche, em especial os bebês. O cenário político local foi desenhado para compreender em que medida tal política trouxe impactos na vida das crianças pequenas da cidade.

$\mathrm{O}$ direito dos bebês às creches se materializa por meio de matrículas e, portanto, não se pode desconsiderar a pertinência de um estudo quantitativo que permita identificar o quanto as crianças estão tendo realmente seus direitos garantidos. As informações contidas no site da prefeitura foram consideradas para analisar o número de matrículas. Isso se deu após o período em que novas inscrições se efetivaram.

Ao longo do período estudado, o município do Rio de Janeiro teve acesso a recursos federais: Fundeb (BRASIL, 2007) e Ação Brasil Carinhoso para a ampliação da rede de educação infantil. De acordo com os dados do programa, houve aumento no número de matrículas de creche (Tabela 1). 
Tabela 1. Brasil Carinhoso - ampliação de matrículas em creche no Rio de Janeiro

\begin{tabular}{|c|c|c|c|}
\hline \multicolumn{2}{|c|}{$\begin{array}{l}\text { Educação infantil } \\
\text { pública - creche }\end{array}$} & \multicolumn{2}{|c|}{$\begin{array}{c}\text { Instituições conveniadas } \\
\text { privadas - creche }\end{array}$} \\
\hline Parcial & Integral & Parcial & Integral \\
\hline 5.123 & 34.543 & 396 & 6.841 \\
\hline
\end{tabular}

Fonte: Relação dos municípios - Brasil Carinhoso (FNDE, 2014).

\section{Creches no Rio de JANEIRo}

As matrículas nas creches públicas, ao longo dos oito anos (2009 a 2016), são apresentadas abaixo, em gráficos produzidos que permitiram entender o desenho e o movimento das matrículas e sua distribuição pelos diferentes grupamentos. Inicialmente, a Secretaria Municipal de Educação do Rio de Janeiro (SME/RJ) organizava a creche com quatro grupamentos: Berçário I (0 a 11 meses); Berçário II (1 ano a 1 ano e 11 meses); Maternal I ( 2 anos a 2 anos e 11 meses); e Maternal II ( 3 anos a 3 anos e 11 meses). Com a nova gestão da cidade iniciada em 2009, mudanças começaram a ser implementadas.

A primeira delas foi a alteração da faixa etária de entrada à creche que, a partir de 2010, passou a ser de três meses completos no período de inscrição. Em 2011, nova alteração determinou a entrada a partir dos seis meses completos, havendo, no mesmo período, fusão nos grupamentos de berçário, que passaram a receber em um único grupamento, sem divisões, crianças de 6 meses a 1 ano e 11 meses. No entanto, para efeito de estatística, os documentos da SME/RJ mantiveram a distinção entre os berçários. Por essa razão, os dados a seguir estão assinalados como Berçário I e Berçário II. O Gráfico 1 apresenta o panorama das matrículas na creche, por grupamento, ao longo dos oito anos estudados (2009 a 2016).

Os dados do Gráfico 1 apontam avanço na oferta de novas vagas, o que impulsionou o crescimento do número de matrículas na creche. No entanto, a distribuição dessas vagas se fez de maneira distinta. O Maternal II apresenta o maior número de matrículas, que vai decrescendo em conformidade com as idades das crianças nos grupamentos. Esse movimento descendente aponta a tendência de maior atendimento às turmas do maternal $\mathrm{e}$ uma diferença importante em relação ao berçário.

$\mathrm{O}$ ano de 2016 apresentou queda no número de matrículas na creche, o que pode ser creditado à obrigatoriedade da pré-escola, definida pela Lei no 12.796 (BRASIL, 2013). Ao longo dos anos, a intencionalidade política esteve voltada para a ampliação do número de matrículas para as crianças de maior idade, com claro desinvestimento para os bebês. Inicialmente, o Berçário
II (1 ano até 1 ano e 11 meses) apresenta uma tímida ampliação para, no ano de 2016, ser reduzida. No Berçário I (crianças de 6 a 11 meses), há uma acentuada diminuição, evidenciando uma política que prezou pela intensa redução no atendimento educacional para os bebês.

Dessa forma, a gestão dupla (2009 a 2016) deixou seu legado para a creche, com crescimento de matrículas no maternal e redução no berçário. O Gráfico 2 permite comparar o cenário encontrado pela nova gestão, em 2009, ao assumir a prefeitura da cidade, com o de 2016, resultado dos efeitos das políticas impressas naquela gestão.

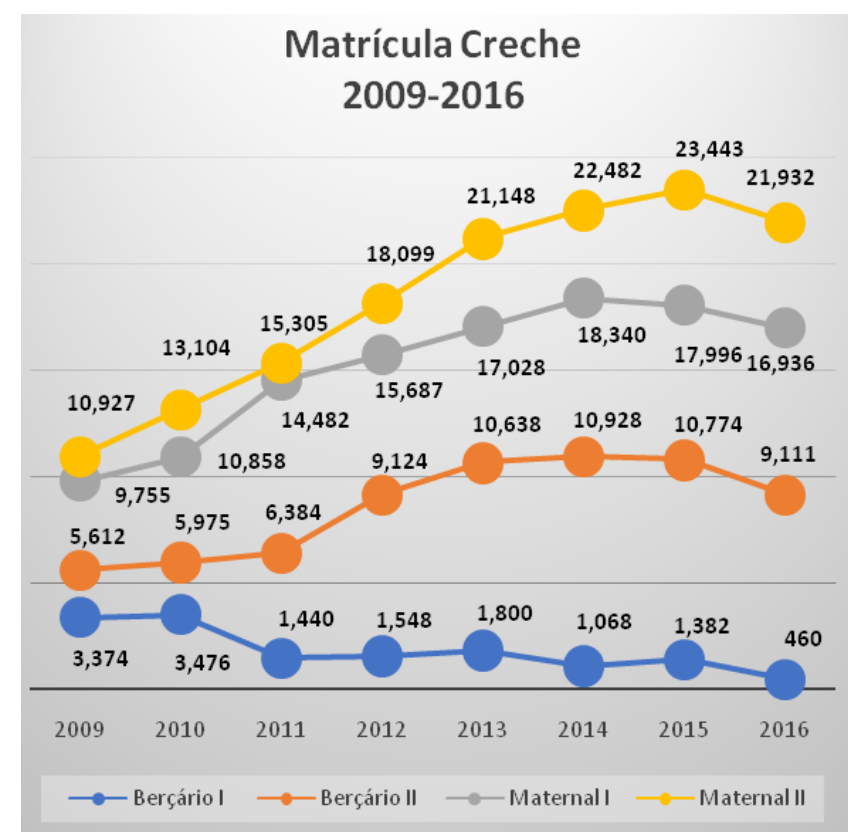

Gráfico 1. Panorama da educação infantil

Fonte: Elaborado pelas autoras.

\section{Creche - comparativo 2009-2016 por grupamento}

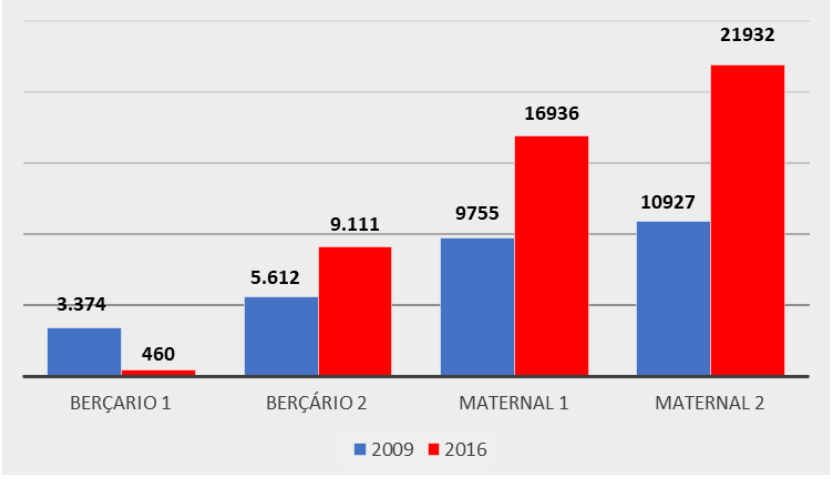

Gráfico 2. Comparativo 2009-2016

Fonte: Elaborado pelas autoras. 
Observando o Gráfico 2, pode-se constatar que a redução do atendimento do Berçário I, ao longo dos anos, traduz a realidade de desresponsabilização com a educação formal dos bebês e a não garantia dos direitos de acesso à educação às crianças pequenas.

No Rio de Janeiro, a realidade do berçário é de extrema fragilidade, evidenciando gradativa desobrigação e ausência de ação política em favor das matrículas dos bebês, mesmo com o recebimento de verba federal relativa ao programa Brasil Carinhoso (BRASIL, 2012).

No entanto, os anos de 2014 e 2015 trouxeram alterações importantes para a creche, em especial a inclusão inédita do horário parcial, além da brusca redução do atendimento. O Gráfico 3 apresenta os Berçários I e II a partir da nova proposta.

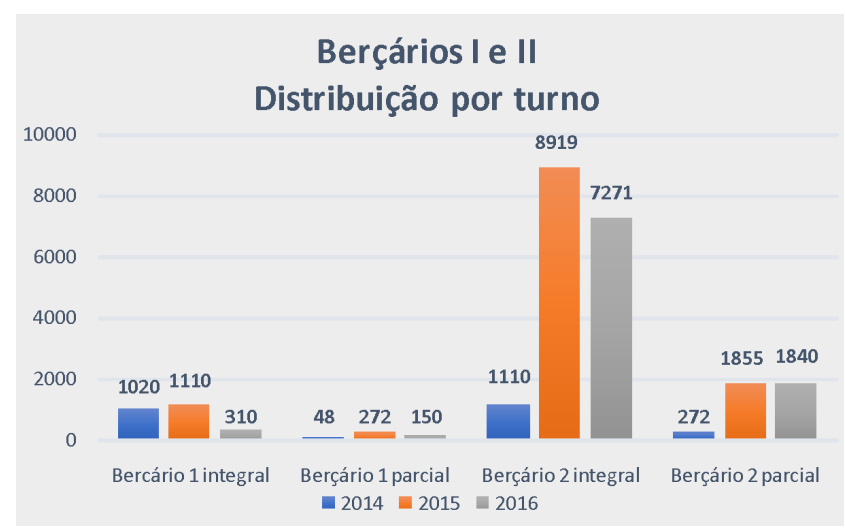

Gráfico 3. Impactos do horário parcial nos Berçários I e II Fonte: Elaborado pelas autoras.

Entretanto, a implementação do horário parcial não fez com que as matrículas dobrassem ou ao menos aumentassem. No Berçário I, inversamente à lógica matemática, houve uma diminuição no atendimento, demonstrando que a estratégia utilizada tinha o intuito de desviar o foco de sua real intenção - reduzir o atendimento aos bebês, descumprindo o dever constitucional com as crianças dessa faixa etária.

A Tabela 2 apresenta o crescimento percentual das matrículas em horário parcial.

Tabela 2. Horário de atendimento no berçário

\begin{tabular}{ccc}
\hline \multirow{2}{*}{ Ano } & \multicolumn{2}{c}{ Atendimento } \\
\cline { 2 - 3 } 2014 & Integral & Parcial \\
2015 & $97 \%$ & $3 \%$ \\
2016 & $83 \%$ & $17 \%$ \\
\hline
\end{tabular}

Fonte: Dados SME/RJ.

A ampliação da idade de entrada na rede municipal e a redução do número de matrículas no Berçário I têm ainda mais impacto quando relacionadas com o crescimento da rede física. Ao assumir a prefeitura, em 2009, o prefeito se compromissou em construir Espaços de Desenvolvimento Infantil (EDI) - edificações pensadas para incorporar creche e pré-escola. Até o ano de 2013, haviam sido construídos 98 EDI chegando a um total de 140 no ano de 2016. Os investimentos realizados na área, no entanto, não contemplaram os direitos dos bebês até 11 meses.

\section{Poder JUdicial}

Há grande demanda por creche na cidade do Rio de Janeiro. A lista de espera do ano de 2016 apontava, só para o berçário, 22.342 crianças aguardando por uma vaga. Diante do cenário de escassez de vagas, algumas famílias buscaram garantir o direito das crianças via processos judiciais, procurando o Ministério Público - Tribunal de Justiça do Rio de Janeiro (TJRJ), que ajuizou a seu favor, por primarem pela observação do direito das crianças. De acordo com Araújo (2015, p. 32):

É o que podemos denominar de uma 'intervenção judicializada' no processo de matrícula, quando, por determinação de juízes e promotores, as instituições e as Secretarias de Educação são obrigadas a matricular crianças por determinação judicial encaminhada pelo Ministério Público, muitas vezes acionada pelas famílias ou pelos Conselhos Tutelares.

Esse exercício de poder constrange gestores e diretores de unidade, obrigando-as a matricular a criança mesmo que a capacidade da turma esteja excedida. As implicações pedagógicas dessa ação podem ser trágicas, com referência à queda da qualidade e até mesmo de segurança das crianças, e cruéis na perspectiva da docência com bebês. Araújo (2017, p. 408) ainda destaca que tais mecanismos acabam produzindo:

[...] formas hierarquizadas e formalizadas de direitos $[\ldots]$ utilizadas para garantir uma estrutura de controle, de socialização e de padronização sistematicamente evocada como mecanismo igualitário de reconhecimento das crianças na vida pública. Assim, espera-se, sob a égide do direito, dissolver as exclusões, sem, contudo, romper com os critérios que desmobilizam a permanente garantia de direitos iguais e inalienáveis, principalmente em situações de desigualdades sociais e dinâmicas de exclusão, como aquelas que ainda se processam na sociedade brasileira.

Os dados aqui apresentados servem de parâmetro para se pensar na situação dos bebês no restante do país. Fala-se de uma capital com rede educacional extensa, com investimentos federais, que conta com a produção de 
conhecimentos de diferentes universidades, mas, apesar disso, opta por secundarizar os bebês na educação.

\section{Alinhando alguns pontos}

Um trabalho com políticas tem consequências para a vida de todos. Este artigo assume o risco de explicitar a realidade de uma gestão. A análise dos dados ajuda a desconstruir discursos políticos, baseados na "confiabilidade" de quem os produz e assim os legitima.

O objetivo foi investigar as políticas públicas de educação infantil na cidade do Rio de Janeiro, em especial aquelas que se traduzem, ou não, em matrículas para creche - berçário. Constatou-se que a formulação e formalização dos direitos nem sempre caminham juntas, gerando discriminação (ARAÚJO, 2017), que pode vir mascarada pela inexistência do reconhecimento social do próprio direito. As autoras do artigo assumem a responsabilidade de contribuir para um novo olhar sobre o direito dos bebês à educação.

É nesse lugar da falta que se encontra a educação dos bebês, nos espaços educacionais públicos na cidade, na gestão 2009-2016. Mais do que silenciados e ignorados, os bebês têm sido subalternizados (SARMENTO, 2005), sempre aguardando que alguém decida a seu favor. Analogamente, está-se diante de um cabo com forças díspares em cada ponta. De um lado, a obrigatoriedade da pré-escola e, de outro, o lado mais frágil da creche - o berçário. Discursos a favor da obrigatoriedade, há muitos, assim como silêncios quando o assunto são os bebês.

Em um país diverso como o Brasil, as leis deveriam considerar as especificidades de cada um e de todos, valorizando situações específicas que são importantes e subjacentes a uma questão ainda maior: o direito de todas as crianças à matrícula em um espaço educativo.

$\mathrm{O}$ artigo aponta indícios de que a obrigatoriedade da pré-escola trouxe impactos na creche carioca, especialmente para o berçário. Os bebês são sujeitos invisíveis no cenário das políticas educacionais, preteridos pela urgência do atendimento às leis que privilegiam as crianças com maior idade. Mesmo após um grande investimento específico da política nacional - Brasil Carinhoso (BRASIL, 2013, e em nível local, Espaços de Desenvolvimento Infantil, RIO DE JANEIRO, 2010) -, as crianças menores (bebês) são colocadas em segundo plano nas propostas educacionais.

Diante desses dados, questiona-se: Rio de Janeiro, cidade maravilhosa para os bebês?

\section{REFERÊNCIAS}

AAÇÃO BRASIL CARINHOSO como estratégia de expansão da oferta e redução da desigualdade educacional na creche Fineduca. Revista de Financiamento da Educação, Porto
Alegre, v. 5, n. 11, 2015. Disponível em: <http://seer.ufrgs.br/ fineduca>. Acesso em: 19 set. 2016.

ARAÚJO, Vania Carvalho de. A impermeabilidade das "políticas" destinadas às crianças: por uma necessária ressemantização do direito. Revista Educação, Porto Alegre, v. 40, n. 3, p. 405-412, 2017.

ARAÚJO, Vania Carvalho de. O tempo integral na educação infantil: uma análise de suas concepções e práticas. In: ARAÚJO, Vania Carvalho de (Org.). Educação infantil em jornada de tempo integral: dilemas e perspectivas. Vitória: Edufes, 2015.

ARENDT, Hannah. A promessa da política. Rio de Janeiro: Difel, 2008.

BRASIL. Base Nacional Comum Curricular. Brasília: MEC, 2017. Disponível em: $<$ http://basenacionalcomum.mec.gov.br $>$. Acesso em: 12 mar. 2018.

BRASIL, Resolução MEC no 1, de 28 de julho de 2016. Aprova as ponderações aplicáveis entre diferentes etapas, modalidades e tipos de ensino da educação básica para vigência no exercício de 2017. Disponível em: <http://www.fnde.gov. br/acesso-a-informacao/institucional/legislacao/item/9435resolu $\% \mathrm{C} 3 \% \mathrm{~A} 7 \% \mathrm{C} 3 \% \mathrm{~A} 3 \mathrm{o}-\mathrm{mec}-\mathrm{n} \% \mathrm{C} 2 \% \mathrm{BA}-1$,-de-28-dejulho-de-2016>. Acesso em: 20 jun. 2017.

BRASIL. Resolução CD/FNDE/MEC no 19, de 29 de setembro de 2014. Estabelece os procedimentos operacionais para a transferência obrigatória de recursos financeiros aos municípios e ao Distrito Federal, a título de apoio financeiro suplementar à manutenção e ao desenvolvimento da educação infantil para o atendimento de crianças de zero a 48 meses informadas no Censo Escolar da Educação Básica, cujas famílias sejam beneficiárias do Programa Bolsa Família, em creches públicas ou conveniadas com o poder público, a partir do exercício de 2014. Disponível em: <http:/www.fnde.gov.br/acesso-a-informacao/ institucional/legislacao/item/6049-resolu $\% \mathrm{C3} \% \mathrm{~A} 7 \% \mathrm{C3} \% \mathrm{~A} 3 \mathrm{o}-$ cd-fnde-mec-n\%C2\%BA-19,-de-29-de-setembro-de-2014>. Acesso em: 15 ago. 2016.

BRASIL. Lei no 13.005 , de 25 de junho de 2014. Aprova o Plano Nacional de Educação e dá outras providências. Disponível em: http://www.planalto.gov.br/ccivi103/ato2011-2014/2014/lei/ 113005.htm. Acesso em: 13 out. 2015.

BRASIL. Ministério da Educação. Portaria Interministerial no 19 , de 27 de dezembro de 2013. Define e divulga os parâmetros anuais de operacionalização do Fundeb para o exercício de 2014. Disponível em: <http://www.fnde.gov.br/acessoa-informacao/institucional/legislacao/item/5147-portariainterministerial-n $\%$ C2\%BA-19,-de-27-de-dezembro-de-2013>. Acesso em: 18 maio 2017.

BRASIL. Presidência da República. Casa Civil. Lei no 12.796, de 4 de abril de 2013. Altera a Lei no 9.394, de 20 de dezembro de 1996, que estabelece as diretrizes e bases da educação nacional, para dispor sobre a formação dos profissionais da educação e dá outras providências. Disponível em: <http://www.planalto. gov.br/ccivil_03/_ato2011-2014/2013/lei/112796.htm>. Acesso em: 13 abr. 2017 .

BRASIL. Lei no 12.722 , de 3 de outubro de 2012. Altera as Leis $\mathrm{n}^{\mathrm{o}} 10.836$, de 9 de janeiro de 2004, no 12.462 , de 4 de agosto de 2011, e no 11.977 , de 7 de julho de 2009; dispõe sobre o apoio financeiro da União aos municípios e ao Distrito 
Federal para ampliação da oferta da educação infantil e dá outras providências. Disponível em: < http://www2.camara. leg.br/legin/fed/lei/2012/lei-12722-3-outubro-2012-774306publicacaooriginal-137757-pl.html>. Acesso em: 22 set. 2017.

BRASIL. Presidência da República. Casa Civil. Emenda Constitucional no 59, de 11 de novembro de 2009. Disponível em: <http://www.planalto.gov.br/ccivil_03/constituicao/ emendas/emc/emc59.htm>. Acesso em: 27 mar. 2016.

BRASIL. Lei no 11.494, de 20 de junho de 2007. Regulamenta o Fundo de Manutenção e Desenvolvimento da Educação Básica e de Valorização dos Profissionais da Educação (Fundeb), de que trata o art. 60 do Ato das Disposições Constitucionais Transitórias; altera a Lei no 10.195, de 14 de fevereiro de 2001; revoga dispositivos das Leis $\mathrm{n} \times$. 9.424, de 24 de dezembro de 1996, n⿳0 10.880, de 9 de junho de 2004, e no 10.845 , de 5 de março de 2004, e dá outras providências. Disponível em: <http:/www.planalto.gov.br/ccivil_03/_ato2007-2010/2007/ lei/111494.htm>. Acesso em: 12 jan. $201 \overline{7}$.

BRASIL. Presidência da República. Casa Civil. Lei no 9.394, de 20 de dezembro de 1996. Estabelece as diretrizes e bases da educação nacional. Diário Oficial da União, Brasília, DF, 23 dez. 1996. Disponível em: <http://www.planalto.gov.br/ ccivil_03/LEIS/19394.htm>. Acesso em: 13 mar. 2017.

BRASIL. Estatuto da Criança e do Adolescente. Câmara dos Deputados. Lei n. 8.069, de 13 de julho de 1990. Diário Oficial da União, Brasília, DF, 10 de jul. 1990 Disponível em: <http:// www.planalto.gov.br/ccivil_03/leis/18069.htm>. Acesso em: 13 mar. 2017.

BRASIL. Constituição (1988). Constituição [da] República Federativa do Brasil. Brasília: Senado Federal, 1988. Disponível em: <http://www.planalto.gov.br/ccivil_03/constituicao/ constituicao.htm>. Acesso em: 13 mar. $2017^{-}$.

BRASIL. Decreto-lei no 4.830, de 15 de outubro de 1942. Estabelece contribuição especial para a Legião Brasileira de Assistência e dá outras providências. Disponível em: <http:// www2.camara.leg.br/legin/fed/declei/1940-1949/decreto-lei4830-15-outubro-1942-414830-publicacaooriginal-1-pe.html>. Acesso em: 30 jul. 2016.

BRASIL. Decreto no 17.943-a, de 12 de outubro de 1927. Institui o Código de Menores. Disponível em: <http://www2. camara.leg.br/legin/fed/decret/1920-1929/decreto-17943-a-12outubro-1927-501820-norma-pe.html>. Acesso em: 13 mar. 2017.

CASTRO, Lucia Rabello de. A aventura urbana: crianças e jovens no Rio de Janeiro. Rio de Janeiro: 7 Letras, 2004.

DAMATTA, Roberto. A casa e a rua: espaço, cidadania e mulher no Brasil. Rio de Janeiro: Rocco, 1997.

FERREIRA, Manuela. A gente gosta é de brincar com outros meninos: relações sociais entre as crianças num jardim de infância. Porto: Edições Afrontamento, 2004.

GIL, Márcia de Oliveira Gomes. Políticas públicas de Educação Infantil na cidade do Rio de Janeiro: berçário em foco (2009 a 2016). 2018. 208 f. Tese (Doutorado em Educação) - Universidade do Estado do Rio de Janeiro (Proped), Rio de Janeiro, 2018.
LANTER-LOBO, Ana Paula Santos Lima. Políticas públicas para a educação infantil: uma releitura na legislação brasileira. In: VASCONCELLOS, Vera Maria Ramos de (Org.). Educação da infância: história e política. Niterói, RJ: Eduff, 2011. p. 133-164.

MÜLLER, Fernanda. Retratos da infância na cidade de Porto Alegre. 2007. 218 f. Tese (Doutorado em Educação) - Programa de Pós-Graduação em Educação, Universidade Federal do Rio Grande do Sul, Porto Alegre, 2007.

NUNES, Deise. Reconhecimento social da infância no Brasil: da menoridade à cidadania. In: VASCONCELLOS, Vera Maria Ramos de (Org.). Educação da infância: história e política. 2. ed. Niterói, RJ: Eduff, 2011. p. 107-132.

PEREZ, Jose Roberto Rus; PASSONE, Eric Ferdinando. Políticas sociais de atendimento às crianças e aos adolescentes no Brasil. Cadernos de Pesquisa, v. 40, n. 140, p.649-673, maio/ago. 2010.

RIO DE JANEIRO. Plano Estratégico da Prefeitura do Rio de Janeiro, 2009 a 2012. Rio de Janeiro. Disponível em: $<$ http://www.rio.rj.gov.br/dlstatic/10112/6616925/4178940/ planejamento_estrategico_site_01.pdf $>$. Acesso em: 12 jul. 2016.

ROSEMBERG, Fúlvia. A criança pequena na agenda de políticas para a infância: representações e tensões. Disponível em: <http://www.diversidadeducainfantil.org.br/PDF/A\%20 CRIANÇA \%20PEQUENA \%20NA\%20AGENDA \%20DE $\% 20$ POLÍTICAS $\% 20$ PARA $\% 20$ A $\% 20$ INFÂNCIA $\% 20 \% 20$ Fúlvia\%20Rosemberg.pdf>. Acesso em: 15 maio 2016.

ROSEMBERG, Fúlvia. A educação pré-escolar brasileira durante os governos militares. Cadernos de Pesquisa, São Paulo, n. 82, p.21-30, ago. 1992.

SARMENTO, Manuel Jacinto. Visibilidade social e estudo da infância. In: VASCONCELLOS, Vera Maria Ramos de; SARMENTO, Manuel Jacinto. (Org.). Infância (in)visível. Araraquara, SP: Junqueira \& Marin, 2007.

SARMENTO, Manuel Jacinto. Crianças: educação, culturas e cidadania activa refletindo em torno de uma proposta de trabalho. Perspectiva, Florianópolis, v. 23, n. 1, p. 17-40, jan./ jul. 2005. Disponível em: <https://periodicos.ufsc.br/index.php/ perspectiva/article/download/9857/9109>. Acesso em: 18 ago. 2017.

TATAGIBA, Ana Paula. Percursos de uma luta urgente: a educação infantil como dever do Estado. Ser Social, Brasília, v. 13, n. 29, p. 146-171, jul./dez. 2011.

TONUCCI, Francesco. Ciudades a escala humana: laciudad de los niños. Revista de Educación, Roma, n. esp., p. 147-168, 2009.

Recebido em 28.05.2018

Aprovado em 09.07.2018

Endereço para correspondência:

Marcia de Oliveira Gomes Gil

Universidade do Estado do Rio de Janeiro (UERJ)

Rua São Francisco Xavier, 524, 12o andar, sala 12037 - F (PROPED)

20550-900 Maracanã, RJ, Brasil 